
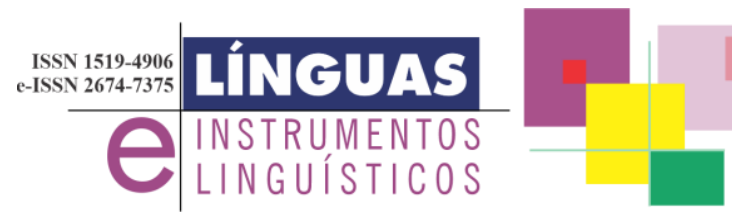

DOI: $10.20396 /$ lil.v24i47.8666703

\title{
Um percurso de leitura pela revista Línguas e Instrumentos Linguísticos
}

\section{A reading route through the journal Language and Linguistics Instruments}

\author{
Vinícius Massad Castro* \\ UFTM
}

\begin{abstract}
Resumo: Nesta resenha, fazemos um percurso de leitura pela revista Lingua e Instrumentos Linguísticos (LIL) com o objetivo de levantar os artigos inscritos na área "Saber Urbano e Linguagem" publicados ao longo de seus 46 números. Consideramos que a publicação de tais artigos constrói a história recente da revista que hoje compõe o quadro de periódicos eletrônicos do Laboratório de Estudos Urbanos (LABEURB), fundado por Eni Orlandi em 1992, junto ao Núcleo de Desenvolvimento da Criatividade (NUDECRI) da UNICAMP.
\end{abstract}

Palavras-chave: Palavras-chave: Linguas e Instrumentos Linguísticos, Saber urbano e linguagem, História.

Abstract: In this academic review, we take a reading route through the journal Language and Linguistics Instruments (LIL) with the aim of surveying the papers enrolled in the "Urban Knowledge and Language" area published over its 46 numbers. We consider that the publication of such papers builds the recent history of the journal that nowadays belongs to the board of electronic journals published by the Laboratory of Urban Studies (LABEURB), founded by Eni Orlandi in 1992, alongside the Center of the Development of Creativity (NUDECRI) from UNICAMP. 
Keywords: Language and Linguistics Instruments, Urban knowledge and language, History.

A Revista Línguas e Instrumentos Linguísticos é um dos resultados do processo de institucionalização da História das Ideias Linguísticas (HIL) como área de estudo dos cursos de graduação e pós-graduação em Letras e Linguística no Brasil. Na história desse processo, destacamse os projetos HIL firmados com apoio Capes/Cofecub entre universidades brasileiras e francesas a partir de 1992. No primeiro projeto, coordenado por Eni Orlandi, na Unicamp, e Sylvain Auroux, na Paris VII, os pesquisadores brasileiros se propuseram a investigar como a produção do conhecimento sobre a língua, o saber metalinguístico, constitui a formação da língua nacional, considerando esses dois processos como indissociáveis (ORLANDI, 2001, p.12).

Os resultados do primeiro projeto HIL mostraram que a constituição da língua nacional no Brasil ocorre num embate tenso que pode ser observado na relação entre o português de Portugal, como língua de colonização imposta, e a constituição de um português brasileiro, afetado pelas línguas indígenas, línguas africanas, línguas gerais e as línguas de imigração. Tal embate seria próprio da contradição entre a diversidade de línguas existentes em território brasileiro e a unidade linguística almejada pelo Estado. Contradição esta que não é administrada, pode compreender Orlandi (1998), sem a configuração de políticas linguísticas, sejam enquanto projetos formais (de cunho claramente organizacional), sejam enquanto projetos informais (implícitos, por exemplo, em usos diferenciados das línguas).

Em cada projeto, as políticas linguísticas podem tratar de modo diferente a contradição unidade/diversidade. Línguas podem ser excluídas, anuladas, dominadas, valorizadas, até mesmo a contradição, uma vez reconhecida, pode ser apagada, exclusivamente a favor de uma unidade. As políticas linguísticas têm, portanto, nos explica Orlandi (1998), implicações éticas e, para a autora, o seu princípio "está justamente não em apagar, mas em trabalhar a contradição unidade/diversidade" (ORLANDI, 1998, p. 12). A reflexão da autora é ainda mais profunda ao explicar que o embate unidade/diversidade não 
é exclusivo da constituição da língua nacional, mas condição necessária da constituição de qualquer língua.

Essas reflexões de Orlandi (1998) estão publicadas sob a forma de artigo intitulado Ética e política linguística. Suas ideias apresentam as bases do segundo projeto HIL, desenvolvido entre 1996 a 2003, que também contou com a coordenação de Diana Luz Pessoa de Barros, na USP. É no curso desse segundo projeto que a Revista Línguas e Instrumentos Linguísticos (doravante LIL), contando com três seções distintas, seção de artigos científicos, crônicas e controvérsias, e resenhas, é lançada por Eduardo Guimarães e Eni Orlandi, seus editores até hoje. O artigo Ética e política linguística abre a seção de artigos científicos do primeiro número da revista, tornada pública no primeiro semestre de 1998. Com esta última edição, a LIL conta com um total de 47 números publicados.

Até a edição de número 20, referente ao segundo semestre de 2007, a LIL foi publicada em versão impressa pela Editora Pontes. A partir da edição do primeiro semestre de 2008, número 21, a revista ganhou uma versão eletrônica, publicada pela Editora RG no site revistalinguas.com. Ainda hoje, a LIL é publicada nesse site, mas desde 2018 encontra-se em processo de migração para a plataforma OJS mantida pelo portal de periódicos eletrônicos da Unicamp. Essa mudança ocorre por conta da passagem da LIL, oficializada em 2019, para o quadro de periódicos eletrônicos do Laboratório de Estudos Urbanos (LABEURB) do Núcleo de Desenvolvimento da Criatividade (NUDECRI) da Unicamp.

A história entre a revista LIL e o LABEURB/NUDECRI, no entanto, não começa em 2019. Como nos ensina Orlandi (2001, p.18): "Toda história começa sempre antes".

Embora seja fruto do processo de institucionalização da HIL, a LIL nunca se restringiu a publicar estudos do campo da HIL. É o que nos mostra a formulação de seus objetivos na apresentação da edição de $n^{\circ}$ 1, em 1998, e a reformulação de seus objetivos no site de publicação eletrônica a partir do $\mathrm{n}^{\circ} 21$, em 2008, mantidos ainda hoje na nova plataforma junto ao LABEURB:

Seu objetivo é publicar textos que apresentam reflexão teórico-metodológica na área dos estudos da linguagem; estudos de história das ideias 
linguísticas e de política das línguas; análises linguísticas de línguas diversas; estudos sobre as variadas instrumentações da linguagem como dicionários, gramáticas, artefatos pedagógicos, bem como outros aspectos de interesse aos estudos linguísticos (LIL, 1998, p. 5).

A revista Línguas e Instrumentos Linguísticos tem como objetivo publicar textos que reflitam sobre a linguagem, sobre $\mathrm{o}$ funcionamento linguístico em geral, sobre as tecnologias da linguagem e sobre a história das ideias, dos conceitos e métodos dos estudos sobre a linguagem. Na realização deste objetivo este periódico tem, com continuidade e regularidade, publicado artigos das diversas áreas das ciências da linguagem e de autores das mais diversas universidades e centros de pesquisa do Brasil e do exterior (LIL, 2008).

A abertura do escopo de publicação da LIL para além dos estudos do campo da HIL pode estar ligada ao fato de os projetos HIL, desde o seu início no Brasil, contarem com pesquisadores de diferentes áreas da Linguística ${ }^{1}$. A seção de artigos científicos das primeiras edições da LIL, números 1 e 2, publicadas em 1998, mostram isso. No número 1, ao lado do artigo Ética e política linguística de Eni Orlandi, inscrito no campo da análise de discurso, encontramos o artigo de Aryon Rodrigues, inscrito no campo da linguística indígena, intitulado $O$ conceito de língua indígena no Brasil, I: os primeiros cem anos (15501650) na Costa Leste, e o artigo de Charlotte Galves, inscrito na área de sintaxe gerativa, intitulado A gramática do português brasileiro. No número 2, encontramos o artigo intitulado Norma e condescendência; ciência e pureza, inscrito no campo dos estudos sociolinguísticos, de autoria de Emílio Pagotto.

Enfim, o interesse da LIL sempre esteve em publicar, além dos estudos em HIL, diferentes estudos da língua e da linguagem, tendo, por isso, como indicado na reformulação dos objetivos em 2008, "publicado artigos das diversas áreas das ciências da linguagem e de autores das mais diversas universidades e centros de pesquisa do Brasil 
e do exterior". Assim sendo, a LIL sempre se configurou como um periódico no qual estudos da área "Saber Urbano e Linguagem", puderam ser abrigados ao lado dos estudos de HIL e outros estudos linguísticos. A área "Saber Urbano e Linguagem" e o LABEURB estão diretamente ligados. Os dois foram fundados ao mesmo tempo em função do desenvolvimento, iniciado em 1992, do projeto "Sentidos do Público no Espaço Urbano" coordenado por Eni Orlandi junto ao NUDECRI.

Partindo da compreensão do espaço urbano como espaço simbólico, produzido pelo modo como a "linguagem se "espacializa" de forma particular na cidade, ganhando suas especificidades, organizando-se em diferentes lugares de interpretação (rua, centro, comércio, praça, muros etc.)" (ORLANDI, 1996a apud GUIMARÃES, 2013, p. 171), os estudos da área "Saber Urbano e Linguagem" buscam "explicitar os diversos funcionamentos de linguagem que instituem o espaço urbano e que definem os lugares de significação/interpretação a partir dos quais esse espaço é vivenciado" (ZOPPI FONTANA, 1997, p. 197). Mesmo contando, desde 1995, com a Revista RUA para abrigar os resultados de suas pesquisas, artigos desenvolvidos no âmbito da área "Saber Urbano e Linguagem" podem ser encontrados desde as primeiras edições da LIL até as mais recentes.

Na edição de número 3, publicada no primeiro semestre de 1999, já encontramos um artigo que se inscreve na área "Saber Urbano e Linguagem". Em Uma balada em toponímia: da Rua Descartes à Rua de Rennes, Bernard Bosredon, pesquisador francês que colaborou nas pesquisas do LABEURB (cf. GUIMARÃES, 2013), analisa os nomes de vias urbanas e rodoviárias de Paris considerando-os como resultados de uma sinalética: "atividade de nomeação de objetos únicos submetida a restrições pragmáticas locais” (BOSREDON, 1999, p. 8).

A estrutura sintática da sinalética dos nomes de via urbana pode ser formada por preposição (p. ex., Rua de Rennes) ou justaposição (p. ex., Rua Descartes). Enquanto o primeiro implicaria uma significação no nível do referente, uma localização direcional topográfica (Rue de Rennes é a rua que conduz à cidade de Rennes), o segundo implicaria uma semântica mais abstrata, na qual impera cumprir com o suficiente para a denominação ocorrer, a necessidade de que um nome, emprestado de pessoa no caso, diferencie um conjunto de termos categoriais como rue e outros (avenue, boulevard, impasse, etc.). A 
semântica dessa última sinalética, segundo o autor, se aproximaria daquela das vias rodoviárias na qual os nomes são formados apenas por justaposição: a um termo de categoria institucional feminino abreviado ( $\mathrm{N}$ para nationale, $\mathrm{D}$ para departamentale, p.ex.) é justaposto um número (formando N6 ou D12, p.ex.).

Além de artigos que se inscrevem na área "Saber Urbano e Linguagem", não será incomum encontrar nas edições da LIL artigos que se inscrevem, ao mesmo tempo, nas áreas "Saber Urbano e Linguagem" e HIL, trabalhando os dois campos conjuntamente. Há também artigos que se inscrevem no campo da HIL ou da semântica e, por analisar objetos de interesse aos estudos do saber urbano, trazem, de alguma forma, contribuições para área "Saber Urbano e Linguagem". Há ainda artigos que se inscrevem no campo da HIL e mobilizam conceitos da área "Saber Urbano e Linguagem" para contribuir com seu desenvolvimento. Foi possível observar esse conjunto de artigos fazendo um percurso de leitura pela seção de artigos científicos das 46 edições já publicadas da LIL. São os artigos desse conjunto que passamos a resenhar brevemente a seguir.

Na edição de número 7, publicada em 2002, está publicado o artigo Sentidos para sujeito e língua nacionais, resultado da tese de Claudia Castellanos Pfeiffer, pesquisadora do LABEURB. Tomando como corpus documentos da historiografia da educação brasileira publicadas na passagem do século XIX para o século XX, Pfeiffer analisa como os discursos que institucionalizam o espaço escolar no Brasil determinam a constituição do sujeito e da língua nacional.

O espaço escolar é reservado para um ser brasileiro assim constituído segundo sua origem e lugar de habitação. Quanto à origem, são excluídos os indígenas e os trabalhadores rurais africanos. Quanto ao lugar de habitação fica excluída a população disseminada pelo interior do país. E é nessa medida que as análises mostram "uma relação fundante entre escolarização e urbanidade. Está apto a ser escolarizado aquele que está urbanizado" (PFEIFFER, 2002, p. 75-76). No espaço urbano, a escola se funda sob o sentido da falta do passado no presente: falta ao "ensino público" laico do presente, regido pelo Estado, o ensino de boa qualidade regido pelo professor jesuíta do passado. Nessa falta, a escola divide os sujeitos entre alfabetizados e analfabetos, sentidos que, balizados pelo Estado para a instauração do lugar do cidadão, colocam a escrita como condição de igualdade. 
Embora não se inscreva diretamente na área "Saber Urbano e Linguagem", o artigo de Sheila Elias de Oliveira intitulado Cidadania: o surgimento da palavra, resultado de sua tese de doutorado, inscrita no campo da HIL, sobre a história da palavra cidadania em dicionários da história da Lexicografia de língua portuguesa no Brasil, contribui para área dos estudos urbanos por meio de suas análises fundamentadas na Semântica do Acontecimento. O artigo foi publicado na edição de número 15 de 2005.

As análises de Elias de Oliveira mostram uma mudança semântica na palavra cidade que comparece nas acepções de cidadão desde o verbete encontrado para essa palavra na $1^{\mathrm{a}}$ edição do dicionário português-latim de R. Bluteau, publicado em 1712. Se desde então ser cidadão de uma cidade era ser cidadão de um Estado do qual se goza de privilégios políticos garantidos juridicamente, na oitava edição do dicionário de A. Moraes e Silva, publicada em 1889, dicionário que se propõe a abreviar Bluteau e torná-lo monolíngue português, os sentidos de cidade e Estado se dividem: ser cidadão é ser morador de uma cidade e ser cidadão de um Estado livre do qual se goza da igualdade de direitos. Ao lado dessa mudança no verbete cidadão, as análises mostram também mudanças no verbete cidade da mesma edição de Moraes e Silva.

Das três acepções que constituíam o verbete cidade, "povoação de graduação superior ás villas", "gente da cidade, assim como de villa, oposta à do campo, e também a de corte, ou cortezã", e "cidade por excelência, diz-se daquela onde estão os que falam", a edição de 1889 de Moraes e Silva suprime a última. Assim "o verbete cidade fixa o sentido de urbs" (ELIAS DE OLIVEIRA, 2005, p. 41) em direção ao sentido do direito igualitário, pois, ao deixar de significar o lugar de alguns que falam, deixa também, com a supressão da terceira acepção, de significar o implícito da existência dos que não falam. Soma-se a isso o exemplo "a cidade revolucionou-se" que personifica a cidade como ator político que pode reivindicar mudanças não pela fala pública, mas pela revolução.

É nesse movimento em que a palavra cidade se fixa sob os sentidos da urbanidade e se separa dos sentidos políticos-civis do Estado que são criadas, no sentido de cidadão, condições para o surgimento da palavra cidadania. Se a palavra cidadão é atestada no português desde o século XII, época em que a língua ainda não se diferenciava do galego, a 
palavra cidadania é registrada, segundo nos explica Elias de Oliveira a partir de informações retiradas do Dicionário Houaiss (2001), pela primeira vez apenas em 1913, na segunda edição do Novo Dicionário da Língua Portuguesa de Cândido de Figueiredo, dicionário lusitano que atribui o surgimento da palavra ao Brasil. A derivação de cidadão para cidadania é resultado de um processo semântico que não deve ser apagado na evidência morfo-etimológica entre as duas palavras, explica a autora.

A edição de número 16, publicada em 2006, apresenta o artigo As palavras, o espaço e a língua: o vocabulário pernambucano de José Horta Nunes que desenvolve uma análise discursiva de uma amostra, publicada em 1976, do Vocabulário Pernambucano escrito por Pereira da Costa no início do século XX, publicado pela primeira vez em 1937. Esse também é um caso de artigo inscrito no campo da HIL, mas que traz contribuições para a área "Saber Urbano e Linguagem".

No Vocabulário, os exemplos que abonam a definição dos verbetes constituem amostras do uso regional da palavra. Eles tomam a forma de provérbios, ditados populares, trechos retirados de textos jornalísticos locais, ditados populares, entres outros. Tais exemplos, ao lado, por exemplo, da origem das palavras indicada como sendo a língua tupi pela citação da obra "O Tupi na Geografia Nacional" de T. Sampaio (tupi que, segundo Sampaio, teria se expandido pelo território brasileiro pelos "conquistadores europeus" e não pela "força de expansão própria da raça primitiva"), ao mesmo tempo que mostram a contradição unidade/diversidade linguística na constituição da língua nacional, deixam entrever, segundo Nunes, "a dicionarização de um espaço urbano, ao contrário do que acontece com instrumentos regionais anteriores" (NUNES, 2006, p.54).

No artigo Cidade e campo: suas designações nos estatutos da cidade e da terra, publicado na edição de número 17 de 2006, José Leonildo Lima analisa a designação proprietário, propriedade, solo e terra no Estatuto da Terra (Lei 4.504 de 30 de novembro de 1964) e no Estatuto da Cidade (Lei 10.257 de 10 de julho de 2001). As análises, fundamentadas na Semântica do Acontecimento, mostram os diferentes sentidos dessas designações que comparecem nos dois estatutos.

O conjunto de palavras significa um lugar jurídico de direito sobre o espaço urbano, no Estatuto da Cidade, e sobre o espaço rural no Estatuto da Terra. Nesse último, no entanto, recebe destaque as 
finalidades econômicas de propriedade, solo e terra como mostram, por exemplo, as designações propriedade da terra economicamente útil, aproveitamento econômico da terra, conservação do solo e corretivo do solo (em oposição à parcelamento e alteração do uso do solo no Estatuto da Cidade), bem como o litígio que designa o termo reforma agrária pelos sentidos da distribuição, concessão e redistribuição de terras. Embora proprietário, propriedade, solo e terra compareçam nos dois estatutos, a análise de Lima mostra como elas significam diferentemente o espaço rural e o espaço urbano.

Na edição de número 18, publicada em 2007, o artigo de Telma Domingues da Silva, intitulado Língua e linguagens: reflexões sobre a política cultural e a televisão brasileira, busca compreender como a institucionalização da área dos estudos da Comunicação, subsidiada pela linguística estrutural e pela semiótica, ao lado do desenvolvimento de uma televisão brasileira junto ao processo de democratização da escola, nas décadas de 1960 e 1970, afetaram a cultura e a constituição de um sujeito urbano escolarizado. Esse artigo de Silva foi desenvolvido no curso do terceiro projeto HIL, "O controle político da representação: uma história das ideias”, ocorrido entre 2005 e 2008 sob a coordenação de Eduardo Guimarães, no Brasil, e Jean-Claude Zancarini, na França.

Como efeito da linguística estrutural na escola, instala-se uma concepção moderna de ensino de português sustentada na ideia de língua como instrumento de comunicação. Essa concepção entra em tensão com o ensino tradicional fazendo com que a gramática deixe de ocupar, para o sujeito, o domínio de instrumento linguístico, para ser secundarizada como livro de consulta em caso de dúvidas localizadas. O objetivo do ensino passa a ser saber usar a língua para se comunicar, tendo como modelo de uso o texto jornalístico e não mais o literário. A televisão, por outro lado, afeta a escola na medida em que a produção audiovisual passa a concorrer com a produção escrita como fonte de cultura e educação do cidadão. Própria de um modelo comercial e não estatal, a educação que a televisão realiza é "a formação de um público consumidor, através da interpelação desse público enquanto sujeito urbano" (SILVA, 2007, p. 97).

Ainda na edição 18 de 2007, o artigo de Jocyare Souza, intitulado Serra das Letras/São Thomé das Letras: designações que enunciam nas relações toponímicas uma forma-sujeito de constituição/identificação 
do cidadão brasileiro, não se inscreve diretamente na área "Saber Urbano e Linguagem", mas traz contribuições para suas reflexões ao analisar, pelo dispositivo da Semântica do Acontecimento, a renomeação da cidade mineira Serra das Letras em São Thomé das Letras. O interesse de Souza sobre o processo de renomeação dessa cidade se deve ao seu estudo sobre nomeações de estabelecimentos comerciais em São Thomé das Letras, nomeações estas que, segundo a autora, são ora construídas com a palavra Letras, ora com o nome São Thomé. A renomeação da cidade rememora o processo de constituição do brasileiro entre a fé católica e o que, aos olhos dessa fé, é considerado profano. Ao passo que São Thomé, está inscrito na enunciação dos nomes de apóstolos de Cristo, a palavra Letras rememora as lendas de surgimento das inscrições encontradas nas pedras de cavernas e grutas da região da cidade.

Na edição 23/24 de 2009, Sheila Elias de Oliveira traz uma segunda contribuição para os estudos urbanos com o artigo intitulado Cidade, ville, cité: três percursos lexicográficos. Fundamentada na Semântica do Acontecimento, Elias de Oliveira analisa a tensão entre os sentidos urbanos e políticos que constituem o verbete cidade nas oito primeiras edições do Dicionário da Língua Portuguesa de Antonio Moraes e Silva, publicados entre 1789 e 1889, e os verbetes ville e cité nas sete primeiras edições do Dicionário da Academia Francesa, publicados entre 1694 a 1878. Essas análises são resultado do pós-doutoramento da autora desenvolvidos no Laboratório Triangle da ENS-LSH de Lyon no quadro do projeto "O controle político da representação: uma história das ideias".

Quanto à cidade, no Dicionário de Moraes, desde sua primeira edição, é possível observar acepções urbanas e políticas. No entanto, como Elias de Oliveira (2005) mostra em Cidadania: o surgimento da palavra, a história de cidade culmina na supressão da acepção política, "cidade por excelência, diz-se daquela onde estão os que falam", e na manutenção das acepções urbanas que significam a cidade como unidade administrativa distinta da villa, e como conjunto de habitantes diferentes dos habitantes da villa, que se opõem aos habitantes do campo e daqueles pertencentes à corte.

Quanto ao verbete cité, no Dicionário da Academia Francesa, uma tensão entre acepções urbanas e políticas se instala a partir da quinta edição, de 1798, rememorando o curso da Revolução Francesa com a 
entrada da acepção "Cité, au propre, se dit de la circonscription locale qui comprend la collection des Citoyens" [Cité, no sentido próprio, se diz da circunscrição local que compreende a coleção de cidadãos] (tradução da autora) e pelo acréscimo da expressão droit de cité. Até então, cité era definida em relação à ville no que dizia respeito ao espaço urbano desta, mais especificamente, em relação a sua arquitetura conforme indica, por exemplo, a primeira acepção de 1694: "Ville. Grand nombre de maison enfermées de murailles" [Ville. Grande número de casas cercadas por muralhas] (tradução da autora). A diferença entre acepções urbanas e políticas em cité permanece até 1878. Entre 1798 a 1878, há tensões na acepção política: ao lado das definições que remetem ao presente francês, comparecem exemplos que remetem à Antiguidade grega; mudanças na definição do droit de cité passam a indicar sua não universalidade e a possibilidade de ganhalo ou perde-lo. Em 1878, há uma especificação nos sentidos urbanos de cité com o acréscimo da expressão "cités ouvrières" [cidades operárias] cujo espaço não é definido em relação ao espaço urbano da ville.

$\mathrm{O}$ verbete de ville é constituído por acepções urbanas, mantendo-se, em todas as edições analisadas do Dicionário da Academia, uma primeira acepção na qual o urbano é significado pelas construções arquitetônicas do espaço: "Assemblage de plusieurs maisons disposées par rües \& fermées d'une closture commune qui est ordinairement de murs \& de fossez" [Conjunto de várias casas dispostas em ruas e fechadas por um entorno comum que é ordinariamente de muros e fossas] (tradução da autora). É no conjunto das expressões trazidas para ilustrar essa primeira acepção que Elias de Oliveira observa sentidos políticos (entre outros que remetem à geografia, costumes, economia, administração e lugares) constituindo os sentidos de ville, como, por exemplo, na frase: "le gouverneur a porté les clefs de la ville au Roy. (...)" [o governador levou as chaves da ville para o rei. (...)] (tradução da autora). Em 1718, são acrescentadas mais duas acepções em que ville é definida pelos sujeitos que ocupam seu espaço: o corpo de oficiais e os habitantes. Em 1832-5, uma última acepção que destaca a oposição da ville com o campo e o modo de vida próprio da ville é acrescentada.

Ainda na edição de números 23/24 de 2009, Neuza Zattar, em artigo intitulado Calçadas: espaços públicos ou privados?, analisa a tensão entre o público e o privado na constituição dos "invasionismos" sobre o espaço das calçada em documentos da história da cidade de Cáceres 
- MT. Entre esses documentos, estão a Ata de Fundação da Villa Maria do Paraguai (1778), primeiro nome dado à cidade, os Código de Posturas, publicados nos séculos XIX e XX, e o Plano Diretor do Município de Cáceres, publicado em 1995.

Por "invasionismo", Zattar (2009, p. 74) chama "Às diferentes formas de ocupação, uso e re-funcionalidade dos espaços públicos das calçadas". As análises da autora mostram ambiguidades na instalação dos limites entre o público e o privado nos documentos mencionados. O texto do Plano Diretor, por exemplo, ao mesmo tempo que entende as calçadas como "logradouros públicos, dotados de passeios", atribui aos proprietários de imóveis a responsabilidade de construção e conservação dos "passeios". Assim, a calçada poderia ser interpretada, tanto como espaço público de livre acesso, quanto espaço privado, de uso particular do proprietário já que dele seria a responsabilidade de construção e conservação. Nessa tensão entre público e privado, a calçada seria significada como território que é, ao mesmo tempo, de todos e de ninguém, o que permitiria as diversas formas de "invasionismos".

Na edição de número 25, publicada em 2010, o artigo Topônimos mineiros: uma análise semântico-enunciativa do processo de ocupação, exploração e formação do Estado Nacional, escrito por Jocyare Souza, analisa, pelo dispositivo teórico da Semântica do Acontecimento, o processo de nomeação e renomeação das cidades do Ciclo de Ouro do estado de Minas Gerais, constituídas entre os séculos XVII e XVIII.

A (re)nomeação das cidades do Ciclo de Ouro, segundo Souza, se deram como diferentes formas de descrição dos espaços visando sua ocupação de modo particular em relação a outros espaços. Por esse processo, os sujeitos ali reunidos poderiam se reconhecer e ser reconhecido como povo "singular", o que lhes garantiria existência, identidade e um modo de evocar, seguindo a compreensão de Guimarães (1992), uma mesma relação de origem entre os ali nascidos. Ainda por esse processo, as (re)nomeações criariam uma relação de pertencimento das cidades e seu povo com o Estado Nacional na medida em que suas enunciações rememorariam a história de ocupação, exploração e formação do Estado Nacional.

Na edição de número 31, publicada em 2013, o artigo Saber linguístico e história urbana: a produção do nós nacional de autoria de 
Carolina P. Fedatto apresenta reflexões resultadas de sua tese de doutoramento defendida em 2011. Considerando que a história de constituição de um saber está sempre articulada ao espaço no qual é produzida, a autora afirma que "A história de constituição do espaço urbano traz, portanto, vestígios da história de produção da língua nacional" (FEDATTO, 2013, p. 78).

A tese defendida por Fedatto é a de que a relação constitutiva entre língua e espaço é um dos fatores de produção do que denomina "saber nacional". Seu artigo analisa discursivamente essa produção observando a diferença dos sentidos das palavras monumento e patrimônio. Patrimônio, inscrita em um discurso jurídico, significaria uma relação familiar de herança que pressupõe uma relação natural entre seus componentes e uma propriedade. Os prédios urbanos investidos sob o sentido de patrimônio fundariam um imaginário de unidade entre os cidadãos de um país pelo efeito da produção de um nós nacional. A autora, inspirada nas reflexões de Émile Benveniste sobre os pronomes pessoais, caracteriza o nós nacional como um nós inclusivo que produz "um plural de igualdade" pela qual a delimitação de uma nação em relação a outras pode ser significada.

A partir da edição de número 33, publicada em 2014, a LIL passou a contar com uma nova seção de artigos científicos chamada Dossiê. Trata-se de uma seção que recebe artigos de pesquisadores convidados por um ou mais pesquisadores a escreverem sobre uma temática específica. Os pesquisadores convidantes ficam responsáveis por organizar o Dossiê.

Na edição de número 34 de 2014, no Dossiê intitulado Diferentes objetos simbólicos em análise, organizado por Greciely Cristina da Costa (atual editora adjunta da LIL e pesquisadora do LABEURB), o artigo Parkour: corpo e espaço reescrevem o sujeito, de autoria de Eni Orlandi, busca compreender o parkour como escrita do sujeito feita por seu próprio corpo na textualização urbana do espaço da cidade.

O traçado do corpo operado pelo parkour caracterizaria um processo denominado por Orlandi de "narratividade". Processo de construção identitária pela qual uma memória "se diz" na medida em que, pelo traço do corpo, prática discursiva específica, o sujeito afirma sua existência no espaço de interpretação determinado da cidade. O parkour, explica Orlandi, ressignifica o espaço urbano "desorganizando o que o consenso administrativo, ao gerir as políticas públicas, 
estabiliza" (ORLANDI, 2014, p. 83). Por outro lado, ressignifica o próprio corpo na medida em que, pela trilha deixada pelo salto, pelo pulo, o sujeito busca dar outra forma material para ele na qual a humana e a animal se aproximam. Para Orlandi, o parkour reescreve o sujeito, pois sua narratividade desenvolve uma forma muito específica da relação corpo-cidade significar.

No mesmo Dossiê organizado no número 34, o artigo $O$ traço das relações sociais no desenho da cidade escrito por Cristiane Dias, pesquisadora do LABEURB, analisa um desenho produzido por um adolescente participante da oficina de informática do projeto Barracão, projeto de extensão e pesquisa desenvolvido pelo LABEURB em bairros periféricos da cidade de Campinas. Dias se questiona como a cidade e suas relações sociais são significadas no desenho.

No desenho, a cidade significa como espaço do trânsito no qual visualizamos a rua, a calçada com uma árvore e um carro parado em frente a uma faixa de pedestre que, em uma ponta se encontra uma pessoa armada e, na outra ponta, uma pessoa com as mãos para cima, como se estivesse rendida. Segundo Dias, esses elementos mostram um imaginário de cidade na qual as relações sociais são reguladas pela violência. Apoiada em Harvey (2000), para o qual a figura da cidade e da utopia se misturam, a utopia que, segundo Dias, constitui, e ao mesmo tempo individua o autor do desenho, seria a do sentido da "violência como im-possibilidade de circulação e de constituição do sujeito da periferia no espaço urbano" (DIAS, 2014, p. 97).

Na edição de número 36, publicada em 2015, o artigo de Luiza Katia Castelo Branco, intitulado $O$ espaço como forma histórica - o discurso das organizações internacionais sobre línguas, que compõe o Dossiê Línguas e espaços de enunciação, organizado por Mónica Zoppi Fontana, mostra como a área "Saber Urbano e Linguagem" pode contribuir para os estudos em HIL. Para analisar como a Comunidade dos Países de Língua Portuguesa (CPLP), enquanto organização internacional, produz discursos sobre a língua portuguesa segundo um imaginário de homogeneidade, a autora caracteriza a CPLP como um "espaço supranacional" fundamentada na compreensão de Orlandi (2004) sobre o "espaço urbano", na compreensão sobre a forma histórica do espaço proposta por Carolina Rodrigues Alcalá (2011), pesquisadora do LABEURB, e na compreensão de Eduardo Guimarães (2005) sobre o que denomina "espaço de enunciação". Os resultados de 
análise de Branco mostram a singularidade com que os discursos da CPLP apagam o político ao construir os sentidos de comunidade e língua portuguesa.

Estudos da área "Saber Urbano e Linguagem" podem ser encontrados na edição 37 de 2016. No Dossiê Técnica é Ética dos discursos on-line, organizado por Cristiane Dias, pesquisadora do LABEURB, e Marie-Anne Paveau, professora da universidade de Paris 13, Cristiane Dias analisa como se dá a emergência da discursividade digital na forma material do urbano discutindo como a noção de mobilidade urbana significa pelo digital no artigo $A$ materialidade digital da mobilidade urbana: espaço, tecnologia e discurso.

Segundo Dias, a mobilidade urbana seria caracterizada pela "mobilidade densa" e pela "mobilidade rarefeita". A primeira diz respeito ao mover do corpo de um ponto a outro pelo espaço físico que, na cidade, se textualizaria pela normatização de vias e percursos, indicadas, por exemplo, pelas placas de trânsito. A segunda seria o mover-se sem sair do lugar pelo fluxo de dados das redes digitais. A conectividade ligaria essas duas mobilidades fazendo espaço urbano e espaço digital se articularem na produção da forma material da cidade. Para exemplificar esse funcionamento, Dias descreve como os sujeitos significam pontos da cidade por meio de aplicativos que reportam as condições desse ponto (engarrafamento, acidente de trânsito, via danificada etc.). Inspirada na compreensão de Orlandi sobre "forma material" e o processo de "circulação" dos discursos, para Dias, tais aplicativos não seriam simplesmente suportes de comunicação, mas "meios materiais" pois determinariam o processo de circulação dos sentidos que discursivizam a cidade.

Na edição de número 41, publicada em 2018, o artigo A constituição do centro histórico de Cáceres - MT: um acontecimento construído por nomes de ruas, dos autores Mirami Gonçalves Reis e Taisir Mahmudo Karim, analisa a história da nomeação das 25 ruas que constituem o centro histórico da cidade de Cáceres segundo os princípios teóricoanalíticos da Semântica do Acontecimento desenvolvida por Guimarães (2005).

As análises mostram a relação dos nomes de rua com os memoráveis recortados em sua nomeação. Rua Tiradentes e Rua 13 de Novembro, por exemplo, recortam o memorável do passado e da nacionalidade. Esses são nomes de ruas encontrados por todo o Brasil que significam 
o ser brasileiro pela história de acontecimentos ocorridos no país. Rua 6 de Outubro, por outro lado, recorta como memorável narrativa locais, no caso, a data de fundação da cidade. Já Rua Coronel José Dulce, por exemplo, recorta o memorável do poder econômico, na medida em que "José Dulce" nomeava uma casa comercial de importância na cidade na década de 1930. Enfim, haveria ainda um grupo de nomes de rua, na qual se incluem, por exemplo, Rua da Tapagem e Rua 13 de Junho, que recortariam memoráveis do heroísmo brasileiro em eventos ligados à Guerra do Paraguai. Segundo Reis e Karim (2018, p. 159), esses eventos são os que tiveram maior impacto na nomeação das ruas do centro histórico de Cáceres.

Buscando compreender, conforme propõe Cristiane Dias (2011), como a cidade é modificada pelo discurso digital, Guilherme Ferragut analisa duas imagens da ocupação da Avenida Paulista, uma promovida em 2013 pelo MPL (Movimento Passe Livre), e outra promovida em 2016 pelo MBL (Movimento Brasil Livre), em artigo intitulado MPLe MBL: a Avenida Paulista e o movimento antes de p e b-uma reflexão sobre a formação algorítmica publicado em 2019, na edição de número 44 da LIL.

Lembrando que a convocação para as duas ocupações foi feita em páginas de eventos do Facebook, para Ferragut, o que o autor denomina de "formação algorítmica" dessa rede social seria capaz de distribuir as convocações para sujeitos da rede que, segundo essa formação, estariam inscritos nas formações discursivas dominantes em cada ocupação: a antineoliberal, no caso do MPL, e a nacionalista, no caso do MBL. Nas imagens, essas diferenças seriam produzidas pelo efeito de heterogeneidade e homogeneidade marcadas respectivamente, por exemplo, na diversidade de vestimentas das pessoas na imagem de 2013 e na uniformização das pessoas na imagem de 2016 (uniformes da seleção brasileira de futebol ou roupas de cor verde-amarela). Ferragut considera então que "a forma como a formação algorítmica das manifestações fez com que os sentidos circulassem pelo digital implicou em efeitos distintos na ocupação da cidade" (FERRAGUT, 2019, p.130).

Fazendo esse percurso de leituras pela LIL, vemos que a Análise de Discurso e a Semântica do Acontecimento são quadros teóricos predominantes no conjunto dos artigos resenhados. 
Quanto à Análise de Discurso, seu predomínio está diretamente relacionado à coordenação de Eni Orlandi na fundação das áreas "Saber Urbano e Linguagem" e HIL. Orlandi, antes da fundação dessas duas áreas, fundou o campo da Análise de Discurso a partir de suas leituras da obra do filósofo francês Michel Pêcheux e seu grupo. É no quadro teórico-metodológico dos estudos discursivos desenvolvidos a partir dessas leituras que Orlandi propõe tanto o projeto "Sentidos do Público no Espaço Urbano" (que, como dito mais acima, fundará a área "Saber Urbano e Linguagem" e o LABEURB) quanto os dois primeiros projetos HIL coordenados por ela no Brasil.

Quanto à Semântica do Acontecimento, seu predomínio está vinculado ao trabalho de Eduardo Guimarães junto ao LABEURB, bem como ao seu trabalho também fundador da HIL, ao coordenar, entre 2005 e 2008, no Brasil, o projeto "O controle político da representação: uma história das ideias", terceiro dos projetos que conduzem à institucionalização da HIL no país (cf. FERREIRA, 2018). Antes de desenvolver trabalhos junto ao LABEURB e no campo da HIL, Guimarães é fundador dos estudos da Semântica do Acontecimento, teoria semântica estabelecida a partir de seus estudos em Semântica da Enunciação, Análise de Discurso, Pragmática e Filosofia Política.

Esses trabalhos fundadores de Orlandi e Guimarães não ocorreram sem a formação de pesquisadores. Todos os autores e autoras dos artigos da LIL acima resenhados, com exceção de Bosredon, ou foram formados diretamente sob a orientação de Orlandi e Guimarães, ou foram formados sob a orientação de pesquisadores por eles orientados. Hoje, alguns são pesquisadores do LABEURB, outros são pesquisadores de outras instituições brasileiras que continuam, assim como Orlandi e Guimarães, o desenvolvimento da HIL e da área "Saber Urbano e Linguagem". Os artigos resultados de suas pesquisas têm, desde o final da década de 1990, contado com a LIL como um lugar para serem publicados, o que foi, aos poucos, construindo uma história de relação entre a revista e o LABEURB e a faz estar hoje abrigada junto ao laboratório. Conhecer essa história é importante não só para conhecermos os avanços científicos produzidos na HIL e nos estudos do saber urbano, mas também para compreendermos a importância da LIL na preservação do espaço dessas duas áreas no âmbito dos estudos da linguagem no país. 


\section{Referências}

BOSREDON, B. Uma balada em toponímia: da Rua Descartes à Rua de Rennes. Revista Línguas e Instrumentos Linguísticos. Campinas, n. 03, 1999, p.07-20.

BRANCO, L. K. C. O espaço como forma histórica - o discurso das organizações internacionais sobre línguas. Revista Línguas e Instrumentos Linguísticos. Campinas, n. 36, 2015, p. 167-193. Disponível em: https://bit.ly/3gQ2773 Acesso em: 11 jun. 2021. DIAS, C. O traço das relações sociais no desenho da cidade. Revista Línguas e Instrumentos Linguísticos. Campinas, n. 34, 2014, p. 89100. Disponível em: https://bit.ly/2TThBiK Acesso em: 17 jun. 2021. DIAS, C. A materialidade digital da mobilidade urbana: espaço, tecnologia e discurso. Revista Línguas e Instrumentos Linguísticos. Campinas, n. 37, 2016, p. 157-175. Disponível em: https://bit.ly/3cWQSsn Acesso em: 16 jun. 2021.

ELIAS DE OLIVEIRA, S. Cidadania: o surgimento da palavra. Revista Línguas e Instrumentos Linguísticos. Campinas, n. 15, 2005, p.3544.

ELIAS DE OLIVEIRA, S. Cidade, ville, cité: três percursos lexicográficos. Revista Línguas e Instrumentos Linguísticos. Campinas, n. 23/24, 2009, p. 37-55. Disponível em: https://bit.ly/3gO5AEu Acesso em: 21 jun. 2021.

FEDATTO, C. P. Saber linguístico e história urbana: a produção do nós nacional. Revista Línguas e Instrumentos Linguísticos. Campinas, $\mathrm{n}$. 31, 2013, p. 75-89. Disponível em: https://bit.ly/2UuNCy9 Acesso em: 18 jun. 2021.

FERRAGUT, G. MPL e MBL: a Avenida Paulista e o movimento antes de p e b - uma reflexão sobre a formação algorítmica. Revista Línguas e Instrumentos Linguísticos. Campinas, n. 44, 2019, p.112-134. Disponível em: https://bit.ly/3zIyTQ6 Acesso em: 11 jun 2021.

FERREIRA, A. C. F. A análise de discurso e a constituição de uma história das ideias linguísticas do Brasil. Fragmentum. Santa Maria, n. especial, jul./dez. 2018, p.17-47. Disponível em: https://bit.ly/3zJulJb Acesso em: 20 jun. 2021.

GUIMARÃES, E. História de uma área do conhecimento: saber urbano e linguagem. In: GUIMARÃES, E. (Org.). Cidade, linguagem e tecnologia: 20 anos de história. Campinas: LABEURB, 2013, p. 169- 
175. Disponível em: https://www.labeurb.unicamp.br/labeurb20anos Acesso em: 21 maio 2021.

LIMA, J. L. Cidade e campo: sua designação nos estatutos da cidade e da terra. Revista Línguas e Instrumentos Linguísticos. Campinas, n. 17, 2006, p. 55-68.

NUNES, J. H. As palavras, o espaço e a língua: o vocabulário pernambucano. Revista Línguas e Instrumentos Linguísticos. Campinas, n. 16, 2006, p. 43-56.

ORLANDI, E. Ética e política linguística. Revista Línguas e Instrumentos Linguísticos. Campinas, n. 01, 1998, p. 07-16 ORLANDI, E. Apresentação. In: ORLANDI, E. (Org.). História das ideias linguísticas: construção do saber metalinguístico e construção da língua nacional. Campinas: Pontes. Cáceres: UNEMAT, 2001, p. 0720.

ORLANDI, E. Parkour: corpo e espaço reescrevem o sujeito. Revista Línguas e Instrumentos Linguísticos. Campinas, n. 34, 2014, p. 7587. Disponível em: https://bit.ly/2Umb0O1 Acesso em: 18 jun. 2021.

PFEIFFER, C. C. Sentidos para sujeito e língua nacionais. Revista Línguas e Instrumentos Linguísticos. Campinas, n. 07, 2002, p. 7193.

REIS, M. G.; KARIM, T. M. A constituição do centro histórico de Cáceres - MT: um acontecimento construído por nomes de ruas. Revista Línguas e Instrumentos Linguísticos. Campinas, n. 41, 2018, p.138-161. Disponível em: https://bit.ly/2SIWFka Acesso em: 16 jun. 2021

SILVA, T. D. Língua e linguagens: reflexões sobre a política cultural e a televisão no Brasil. Revista Línguas e Instrumentos Linguísticos. Campinas, n. 18, 2007, p. 87-100.

SOUZA, J. Serra das Letras/São Thomé das Letras: designações que enunciam nas relações toponímicas uma forma-sujeito de constituição/identificação do cidadão brasileiro. Revista Línguas e Instrumentos Linguísticos. Campinas, n. 18, 2007, p. 51-62.

SOUZA, J. Topônimos mineiros: uma análise semântico-enunciativa do processo de ocupação, exploração e formação do Estado Nacional. Revista Línguas e Instrumentos Linguísticos. Campinas, n. 25, 2010, p. 25-48. Disponível em: https://bit.ly/3j0FAah Acesso em: 21 jun. 2021. 
ZATTAR, N. Calçadas: espaços públicos ou privados? Revista Línguas e Instrumentos Linguísticos. Campinas, n. 23/24, 2009, p.73-82. Disponível em: https://bit.ly/3gX9IAV Acesso em: 21 jun. 2021.

ZOPPI FONTANA, M. O sentido público no espaço urbano: projeto de pesquisa do Laboratório de Estudos Urbanos. RUA. Campinas, n. 03, 1997, p.149-153. Disponível em: https://bit.ly/3d0ftN1 Acesso em: 21 maio 2021.

\section{Notas:}

* Doutor em Linguística pela Universidade Estadual de Campinas (Unicamp). Professor substituto da Universidade Federal do Triângulo Mineiro (UFTM).

1 "Em nosso caso, temos, na equipe, especialistas das várias áreas da linguística (sintaxe, semântica, análise de discurso, pragmática, sociolinguística, linguística indígena, lexicologia etc.), da filosofia da linguagem, da história, dos estudos clássicos, das ciências da informação e da cognição, e também da literatura" (ORLANDI, 2001, p. 16). 